\title{
DIREITO FUNDAMENTAL INTERDIMENSIONAL AO AFETO
}

\section{Clarissa Maria Beatriz Brandão de Carvalho Kowarski ${ }^{1}$ Samanta Francine Alvarenga ${ }^{2}$}

\section{Resumo}

Os direitos fundamentais dotam-se de historicidade, tanto que são reconhecidos e inseridos em gerações/dimensões. Muito se fala no reconhecimento do afeto pelo Direito com o advento da Constituição Federal de 1988, embora o mesmo não tenha previsão expressa no texto constitucional. $\mathrm{O}$ afeto é inerente à pessoa humana $\mathrm{e}$, portanto, um não pode ser pensado de modo desvinculado do outro, sendo imprescindível à proteção da dignidade humana e ao seu desenvolvimento psíquico. Nesse contexto, o presente artigo tem por objetivo analisar e compreender o afeto como um direito dotado de fundamentalidade e reconhecido em todas as dimensões de direitos fundamentais apontadas pela doutrina atualmente. Trata-se de uma pesquisa teórica e qualitativa, que utiliza como meios as revisões bibliográfica e documental.

Palavras-chave: Direito fundamental; afeto; dimensões.

\section{INTRODUÇÃO}

$\mathrm{Na}$ concepção do que vem a ser um direito fundamental, impende ressaltar que, para assim ser considerado, não é necessário que o direito seja expressamente colocado no rol de direitos fundamentais expresso na Constituição Federal de 1988, nos termos do $\S 2^{\circ}$ do artigo $5^{\circ}$. Os direitos fundamentais apresentam como uma de suas características a historicidade, na medida em que estariam relacionados a um determinado contexto histórico e social. Assim surgem as chamadas gerações ou dimensões de direitos fundamentais - ressalte-se que há autores que falam em três, quatro, cinco e até seis -, donde se percebe a sua dinamicidade e uma fundamentalidade embasada em uma relevância extraída do contexto em tela. Na conjuntura dessa dinamicidade e relevância

\footnotetext{
${ }^{1}$ Professora Associada da Universidade Federal Fluminense. Universidade Federal Fluminense - UFF, Rio de Janeiro - Brasil.; ORCID iD: https://orcid.org/0000-0001-6751-3239 Lattes: E-mail: clarissamariabeatriz@gmail.com

${ }^{2}$ Mestranda no Programa de Pós-Graduação em Direito Constitucional da UFF. Universidade Federal Fluminense - UFF, Rio de Janeiro - Brasil. ORCID iD: Lattes: E-mail: fpasamanta@gmail.com
} 
temporal é que se insere o afeto e questiona-se: é possível afirmar a existência de um direito fundamental interdimensional ao afeto?

Qualquer relação humana e até mesmo a existência humana não podem ser entendidas de forma desprendida do afeto. É desta forma que ao Direito não resta outra alternativa senão a de enlaçar-se ao seu reconhecimento e valor. A Constituição Federal de 1988, nesse sentido, renovase e volta-se à tutela da pessoa humana assegurando, para tanto, principalmente o respeito e a proteção aos direitos fundamentais. O reconhecimento do afeto no cenário jurídico, inclusive, marca-se pelo advento de referida Carta e a necessidade de analisá-lo e compreendê-lo como um direito fundamental interdimensional remonta a questões como a própria proteção dos grupos chamados vulneráveis e das famílias, decorrendo, ainda, da dignidade da pessoa humana e ilustrando o seu valor nas ações de abandono afetivo que vêm assolando os tribunais brasileiros.

Assim, longe de aqui pretender-se um esgotamento do tema, suscita-se a partir de considerações teóricas e jurisprudenciais que, embora não seja reconhecido de modo expresso pela Constituição Federal, o afeto pode ser considerado um direito fundamental, que por ser inerente à pessoa humana, não se restringe à uma única dimensão, mas permeia todas as dimensões de direitos fundamentais consideradas.

Para tanto, a fim de desenvolver o que aqui se propõe, por meio de uma pesquisa teórica qualitativa, são usadas as revisões bibliográfica e documental, dividindo o presente trabalho em três partes.

No primeiro momento, o que se pretende é inserir a própria temática dos direitos fundamentais, abordando suas características e a questão de sua fundamentalidade e dimensões. Passa-se, em seguida, a fim de esboçar a importância do afeto, a abordá-lo no contexto dos grupos chamados vulneráveis e das famílias. Por fim, para arrematar o pretendido, analisa-se o afeto na perspectiva da dignidade da pessoa humana e o caso do chamado abandono afetivo.

\section{DIREITOS FUNDAMENTAIS: DELINEAMENTOS E DIMENSÕES}

De início, a fim de se contribuir para uma inserção do afeto no rol de direitos fundamentais e defender sua interdimensionalidade, fazem-se imperiosas algumas considerações acerca desses direitos. Ademais, importante destacar a opção pela terminologia "direitos fundamentais" em consonância com a adotada pela Constituição Federal Brasileira de 1988 em seu título II denominado “Dos Direitos e Garantias Fundamentais", na mesma diretriz que Ingo Wolfgang Sarlet 
aponta em sua obra "A eficácia dos direitos fundamentais: uma teoria geral dos direitos fundamentais na perspectiva constitucional” (2012).

A história dos direitos fundamentais desemboca no próprio surgimento do moderno Estado constitucional, que se funda no reconhecimento e proteção da dignidade da pessoa humana e nos direitos fundamentais do homem (SARLET, 2012).

Ao tratar da norma de direito fundamental, Alexy (2008, p. 65-76) questiona-se (no contexto da Constituição alemã) o que faz com que um enunciado específico seja considerado uma disposição de direito fundamental. Para ele, a resposta pode basear-se nos aspectos tanto materiais quanto estruturais e/ou formais. Contudo, rejeitando os critérios substanciais e estruturais, o autor aponta para o critério formal e salienta que, em primeiro lugar, as disposições de direitos fundamentais são todas que constavam no capítulo da Constituição Alemã intitulado "Dos Direitos Fundamentais", como também outras disposições constitucionais que expressem normas de direitos fundamentais.

Para Sarlet (2012), os direitos fundamentais constituem-se como aquelas proposições jurídicas tocantes às pessoas, tendo em vista o direito constitucional positivo, e que por seu conteúdo e relevância (para ele fundamentalidade material), foram inseridas no texto da Constituição e excluídas da esfera de disponibilidade dos poderes constituídos (para ele fundamentalidade formal) ou, ainda, as proposições que, por seu conteúdo, são equiparadas e agregadas à Constituição material, mesmo que não tenham assento na Constituição formal.

Assim, nesse contexto, pode-se destacar, então, tanto uma concepção formal como material de direitos fundamentais. Em síntese, direitos fundamentais formais são aqueles que se encontram inseridos de forma explícita no texto constitucional, enquanto os materiais são aqueles que a despeito de sua não inserção, sua fundamentalidade advém de seu próprio conteúdo e consequente relevância.

É nesse sentido que se insere o artigo $5^{\circ}, \S 2^{\circ}$ da Constituição Federal de 1988 , que dispõe que os direitos e garantias expressos não excluem outros que decorrem do próprio regime e princípios que adota, bem como dos tratados internacionais dos quais o país seja parte.

Como características desses direitos pode-se apontar o seu caráter histórico, inalienável, imprescritível e irrenunciável (SILVA, 2002, p. 181). Quanto à historicidade, isto significa que os direitos fundamentais se relacionam ao contexto histórico em que se inserem; a inalienabilidade refere-se ao fato se não ser possível dispor do direito fundamental em si, mas apenas do objeto que corporifica o direito em tela; a imprescritibilidade consubstancia-se no fato de que o não exercício do direito de modo voluntário, por si só, não é motivo para que o direito em comento se perca; e, por fim, a irrenunciabilidade, conforme o próprio termo adianta, é a não possibilidade de rejeitar um direito fundamental, a titularidade sempre se mantém. Ainda, para Alexy (2008, p. 111-117), 
outra característica dos direitos fundamentais seria a relatividade, para o qual nenhum direito fundamental poderá ser tido como absoluto, de modo que, nos casos de colisão, o critério ou método adotado será o da ponderação, cuja precedência se dará levando-se em conta o caso concreto.

O reconhecimento de direitos fundamentais é uma conquista do indivíduo e da sociedade, que se ligam às próprias transformações pelas quais passaram, entre as quais destaca Bobbio (2004): o aumento da quantidade de bens merecedores de tutela; a expansão da titularidade de determinados direitos a sujeitos distintos do homem e a compreensão do homem em suas especificidades e inserido na sociedade.

Considerando-se a própria característica da historicidade dos direitos fundamentais, supracitada, os direitos não são imutáveis, mas sim dinâmicos, fato perceptível pelo próprio tempo. O elenco de direitos se modificou e continua modificando na esteira das mudanças das condições históricas, dos carecimentos e dos interesses (BOBBIO, 2004).

É no contexto dessa historicidade e consequentes e incansáveis transformações pelas quais passaram os direitos fundamentais, tanto de conteúdo quanto titularidade, eficácia e efetividade, que se costuma falar na existência de três gerações desses direitos, ou até mesmo mais gerações, segundo alguns autores. Ainda, em breve síntese, apenas a título explicativo, quanto ao termo "gerações", insurgiram-se críticas, no sentido de que os direitos fundamentais se norteiam por um processo de reconhecimento progressivo e complementar, ao passo que o termo "gerações" denotaria um processo substitutivo (SARLET, 2012). Nessa esteira, aqui se dará preferência pelo uso da expressão “dimensões".

Quanto às três primeiras dimensões (ou gerações), as mesmas relacionam-se à: (i) liberdade; (ii) igualdade; (iii) fraternidade. Os direitos fundamentais de primeira geração ligados ao princípio da liberdade, são também conhecidos como direitos individuais e, destarte, têm como titular o indivíduo e referenciam-se a uma conduta negativa do Estado, relacionados a direitos civis e políticos. Já os direitos de segunda dimensão, correspondem ao período do século XX, caracterizando-se como direitos coletivos perfilhados pelo princípio da igualdade; são os direitos sociais, culturais e econômicos. Os direitos fundamentais de terceira dimensão solidificam-se no final do século XX e são correlatos aos direitos difusos (BONAVIDES, 2004, p. 563-567).

Contudo, como já dito, há autores que falam em outras dimensões (gerações), para os quais haveria uma quarta, quinta e até sexta dimensão, sobre as quais se tecerão breves comentários. No que concerne à quarta dimensão de direitos fundamentais, encontram-se divergências entre quatro autores (MORAES, 2016). Para Eliana Calmon (2001, p. 79) a quarta dimensão de direitos fundamentais estaria relacionada à ideia de patrimônio genético; segundo, para Paulo Bonavides (2004, p. 567-568) os direitos fundamentais de quarta dimensão estariam ligados à globalização econômica, apontando o direito à democracia, o direito à informação e o direito ao pluralismo como 
basilares dessa dimensão; terceiro, para Alberto Nogueira (1997, p. 193) essa dimensão estaria referenciada à tributação justa; e, por fim, Ricardo Lorenzetti $(1998$, p. 154) vincula a quarta dimensão à diversidade, ao direito a ser diferente.

Outrossim, quanto aos direitos de quinta dimensão, importante destaque a José de Oliveira Júnior e Janusz Symonides (MORAES, 2016). Para o primeiro, além de concordar com Eliana Calmon quanto à quarta dimensão, a quinta dimensão de direitos fundamentais estaria ligada à cibernética (OLIVEIRA JÚNIOR, 2000, p. 86); enquanto que Janusz Symonides (2003, p. 32) ratifica a quarta dimensão apontada por Bonavides e aponta o direito à paz como quinta dimensão. Por derradeiro, a sexta dimensão estaria relacionada ao acesso à água potável, segundo os ensinamentos de Zulmar Fachin e Deise Marcelino da Silva (2010, p. 74).

O exposto até aqui consonante aos direitos fundamentais e suas dimensões nos serve para demonstrar a sua dinamicidade e a sua fundamentalidade advinda de sua relevância inserida no contexto histórico e social, no qual exsurge a ideia de novos direitos a permear o ordenamento jurídico. Segundo Sarlet (2012), o processo de reconhecimento desses direitos é essencialmente dinâmico e dialético, caracterizado por avanços, retrocessos e até mesmo contradições, não havendo que se falar em um fundamento absoluto para os direitos fundamentais, mas em uma

[...]evolução que se processa habitualmente não tanto por meio da positivação destes 'novos' direitos fundamentais no texto das Constituições, mas principalmente em nível de uma transmutação hermenêutica e da criação jurisprudencial no sentido do reconhecimento de novos conteúdos e funções de alguns direitos já tradicionais. (SARLET, 2012)

É nesse contexto dinâmico, portanto, que galga cada vez mais importância e reconhecimento, no atual contexto, o afeto, conforme restará demonstrado a seguir.

\section{AFETO, VULNERABILIDADES E FAMÍLIAS}

As relações humanas não existem desvencilhadas do afeto e nesse sentido deve caminhar o ordenamento. A criação de óbices ao reconhecimento jurídico de relações afetivas faz com que o direito elida o aspecto subjetivo que compõe o ser humano, tornando-se inadequado (RODOTÀ, 2015, p. 7).

Não foram poucos os avanços decorrentes da incorporação de valores sociais vigentes ao texto constitucional. Todas as transformações sociais que podem ser verificadas nas últimas décadas têm impacto direto no modo de enxergar e compreender o indivíduo, o que acaba afetando a forma como o Direito com eles se relaciona.

Nesse sentido, ao menos do que se pode perceber em um primeiro momento do ordenamento pátrio, bem como do texto constitucional, o afeto vem alçando de modo gradativo 
uma maior importância no Direito, especialmente no que diz respeito aos chamados grupos vulneráveis e ao Direito de Família.

A pretérita distância que se observava entre a Ciência do Direito e a realidade social, somada à fragilidade e insuficiência das estruturas jurídico-formais, montadas a priori para solucionar os problemas humanos, demonstram uma posterior valorização do afeto no âmbito jurídico, levandose em conta a perspectiva em que se pretende construir um direito voltado às pessoas que integram a sociedade como sujeitos reais e não ideais (BARBOZA, 2009, p. 106).

A Constituição Federal de 1988 marca uma ordem que se volta à tutela da pessoa humana, assegurando direitos fundamentais e consagrando a dignidade da pessoa humana como fundamento do Estado Democrático de Direito.

É no sentido dessa tutela da pessoa humana que surgem os chamados grupos vulneráveis, aqueles que por razão de seus acasos pessoais encontram-se impedidos integralmente ou em parte de exercerem seus direitos, necessitando, portanto, de uma proteção diferenciada e consequentemente uma tutela específica, correspondente aos mais variados aspectos, sejam eles existenciais, sociais e/ou econômicos. (BARBOZA, 2009, p. 114).

É dentro da necessidade dessa tutela específica que exsurge o afeto (familiar e social) como um dos meios para essa proteção diferenciada, o que será demonstrado sob o recorte de três grupos vulneráveis, quais sejam, as crianças e os adolescentes, os idosos e a pessoa com deficiência.

Ademais, podendo-se dizer, inclusive, que de modo complementar, apesar da inexistência de uma previsão da afetividade no texto constitucional, o afeto é entendido pela maioria da doutrina como princípio fundamental ao direito de família e consagrado pela Constituição Federal de 1988.

Tanto os grupos vulneráveis como o próprio Direito de Família trazem em seu bojo a importância que o afeto adquiriu na seara jurídica, o que será ilustrado a seguir.

\subsection{AFETO E A CRIANÇA E O ADOLESCENTE}

A Constituição Federal de 1988 consagrou em seu artigo 227 o melhor interesse da criança e do adolescente, o qual foi reiterado posteriormente pelo Estatuto da Criança e do Adolescente (ECA), Lei $\mathrm{n}^{\mathrm{o}} 8.069 / 1990$, em seus artigos $1^{\circ}$ e 18 , e que permite o integral desenvolvimento da personalidade, concretizando-se como uma diretriz solucionadora de conflitos (DINIZ, 2012, p. 37).

Referido reconhecimento alçaram a criança e o adolescente como sujeitos de direitos a ensejar que se faça prevalecer os interesses destes, devendo os mesmos serem encarados com prioridade perante a sociedade, em virtude de sua vulnerabilidade. 
O significado de serem a criança e o adolescente sujeitos de direitos, significa que deixam de ser tratados como sujeitos passivos e passam a igualarem-se aos adultos quanto à titularidade de direitos fundamentais (PEREIRA, 2008, p. 51).

Quanto ao afeto na tutela da criança e do adolescente esse decorre dos próprios artigos 227 e 229 da Constituição Federal, que dispõem acerca do dever da família e da sociedade na proteção dos mesmos, bem como o dever dos pais à assistência, criação e educação, a qual deve ser interpretada no contexto de um desenvolvimento tanto físico como psíquico, nesta inserida a preservação do afeto.

Outrossim, no Estatuto da Criança e do Adolescente os artigos $3^{\circ}$ e $4^{\circ}$ garantem à criança $\mathrm{e}$ ao adolescente a fruição bem como a efetivação dos direitos fundamentais inerentes à pessoa humana, assegurando-lhes, ainda, o desenvolvimento físico, mental, moral, espiritual e social.

$\mathrm{Na}$ mesma linha, os artigos 15, 17 e 18, ainda asseguram o respeito à dignidade como pessoas humanas, considerados como sujeitos de direitos civis, humanos e sociais, a inviolabilidade da integridade física, psíquica e moral.

Ainda, o artigo 92 do referido dispositivo legal também garante que as entidades que desenvolvam programas de acolhimento familiar ou institucional, no que tange à atuação dos educadores para crianças de 0 a 3 anos, firmando o afeto como uma necessidade básica.

Percebe-se, portanto, a preocupação do constituinte e do legislador com o desenvolvimento não apenas físico, mas também com o desenvolvimento psíquico (intelectual e moral). É nesse contexto que o afeto, como elemento componente da personalidade humana, deve permear a tutela das crianças e adolescentes, entendidas como sujeitos em desenvolvimento e sujeitos de direito, merecendo proteção especial, e garantia do afeto como um direito inerente.

\subsection{AFETO E O IDOSO}

Os idosos apenas angariaram especial reconhecimento com a edição do Estatuto do Idoso, Lei $n^{\circ} 10.741 / 2003$, que passou a conferir proteção integral a esse grupo. Nos termos do artigo $1^{\circ}$ da referida legislação, o idoso é a pessoa com idade igual ou superior a 60 (sessenta) anos.

Os artigos $2^{\circ}$ e $3^{\circ}$ garantem aos idosos os direitos fundamentais inerentes à pessoa humana, devendo assegurar-lhes a preservação de sua saúde tanto física quanto mental, bem como aperfeiçoamento moral, intelectual, espiritual e social, sendo obrigação da família, da sociedade e do Estado garantir-lhes a efetivação desses direitos, com destaque aqui à dignidade e o respeito à convivência familiar e comunitária. 
Ainda, o artigo 10 prevê que é obrigação do Estado e da sociedade assegurar o respeito e a dignidade dos idosos como pessoa humana, bem como sujeito de direito civis, políticos, individuais e sociais, consistindo o respeito na inviolabilidade da integridade física, psíquica e moral.

Portanto, mais uma vez o que se percebe é a preocupação não apenas com o físico, mas também a situação psíquica da pessoa humana, no caso específico, o idoso. Sérgio Resende de Barros ressalta que o artigo 230 da Constituição Federal envolve o idoso do afeto constituinte, espelhando o afeto familiar e o afeto social que por eles mantêm todos que deles nasceram ou conviveram ao longo da vida (BARROS, 2004, p. 617).

O que se pretende mais uma vez demonstrar é a importância dada ao indivíduo enquanto ser humano e enquanto sujeito de direitos, merecendo proteção em todas as suas esferas, sejam elas patrimoniais, sociais ou existenciais, denotando-se daí a relevância do olhar o outro com afeto e garantir-lhe o afeto, inserido nessas esferas.

\subsection{AFETO E A PESSOA COM DEFICIÊNCIA}

A fim de garantir o exercício dos direitos e liberdades fundamentais das pessoas com deficiência, foi instituído o Estatuto da Pessoa com Deficiência, Lei no ${ }^{\circ} 13 \cdot 146 / 2015$. Nos termos de seu artigo $2^{\circ}$ é considerada pessoa com deficiência aquele que possui impedimento de longo prazo, seja de natureza física, intelectual ou sensorial, que podem obstaculizar a participação plena em condições de igualdade a vida em sociedade.

No que concerne às pessoas com deficiência o Estatuto marca uma mudança paradigmática que passa a permitir que essas pessoas sejam compreendidas e incluídas em relação ao Direito e à Justiça, marcando, ainda, uma alteração no modelo médico, no qual o foco se dava na doença; para um modelo social que centra as preocupações no indivíduo paciente e suas necessidades, tornando corresponsáveis a família, a sociedade e o Estado.

$\mathrm{O}$ artigo $4^{\mathrm{o}}$ do Estatuto, prevê o direito à igualdade de oportunidades vedando qualquer forma de discriminação, protegendo a titularidade e o exercício dos direitos e liberdades fundamentais à pessoa com deficiência. Ainda, o artigo $6^{\circ}$ em seus incisos, efetiva a plena capacidade civil dessas pessoas para casar ou constituir união estável; exercer direitos sexuais e reprodutivos; liberdade no planejamento familiar; conservação da sua fertilidade; exercer o direito à família e convivência familiar e comunitária; bem como exercer direito à guarda, tutela, curatela e adoção. Nessa mesma linha o artigo $8^{\circ}$ assevera como dever do Estado, da sociedade e da família assegurar às pessoas com deficiência a efetivação dos direitos, entre os quais, destaca-se, à 
sexualidade, à paternidade e maternidade, à dignidade, ao respeito e à convivência familiar e comunitária.

$\mathrm{Na}$ Constituição Federal a tutela às pessoas com deficiência estende-se pelos artigos $7^{\circ}$, XXXI; 23, II; 24, XIV; Art. 37, VIII; 203, IV; 208, III e IV; 227, §1 ${ }^{\circ}$, II e $§ 2^{\circ}$ e 244 . Todos os artigos referenciados, especialmente o Estatuto da Pessoa com Deficiência, denotam como o indivíduo atinge seu destaque e passa a ser o foco não apenas com relação a questões patrimoniais, mas principalmente a questões afetivas.

\subsection{AFETO E FAMÍLIAS}

Com a Constituição Federal de 1988 a família passa por uma sensível transformação na medida em que o afeto passa a ser a base da família, constituindo em uma escala de fundamentalidade o primeiro dos direitos humanos da família, seguido pelo direito ao lar, cuja essência é o próprio afeto (BARROS, 2004, p. 613).

Assim, a Constituição Federal de 1988 é tida como marco inicial da inserção do afeto no cenário jurídico (CALDERÓN, 2017), reconhecendo-o, mesmo que de forma implícita, nos seguintes dispositivos: artigo $226, \S \S 3^{\circ}$ e $4^{\circ}$, em que se reconhecem a união estável e a família monoparental (formada por qualquer dos pais e seus descendentes); no artigo 227 , caput, e $\S \S 5^{\circ} \mathrm{e}$ $6^{\circ}$, que estabelecem a adoção a ser assistida pelo Poder Público e a igualdade entre os filhos biológicos e adotivos (DIAS, 2013, p. 72).

Já no Código Civil a referência ao afeto pode ser inferida do artigo 1.593, em que se prevê que o parentesco pode ser natural ou civil conforme resulte de consanguinidade ou outra origem. Também na legislação esparsa, no contexto familiar, merecem destaque o Estatuto da Criança e do Adolescente (já mencionado), a Lei Maria da Penha (Lei no 11.340/06); a Lei de Adoção (Lei n ${ }^{\circ}$ 12.010/09), a Lei Clodovil (Lei $\left.n^{\circ} 11.924 / 09\right)$ e a Lei de Alienação Parental (Lei nº11.924/09) (CALDERÓN, 2017).

No Estatuto da Criança e do Adolescente denotando a importância do afeto, o $\S 1^{\circ}$ do artigo 41 do Estatuto da Criança e do Adolescente, chancelado com o reconhecimento da jurisprudência, passa a reconhecer a existência de encargos e do direito de visita do padrasto (pai afetivo), com fundamento no vínculo afetivo; outrossim, a Lei $n^{\circ} 11.924 / 2009$, conhecida como Lei Clodovil, passa a permitir a adoção pelo enteado (a) do nome do padrasto/madrasta.

Já na Lei $\mathrm{n}^{\circ}$ 11.340/06, a chamada Lei Maria da Penha, traz em seu texto de modo explícito o afeto. Seu artigo $5^{\circ}$, inciso III, prevê a configuração de violência doméstica, inclusive, em 
qualquer relação íntima de afeto ${ }^{3}$. A violência familiar acaba por representar um tipo de intolerância evidenciada pelo modelo social do presente, uma vez que a transformação do ambiento destinado ao afeto em um ambiente de agressões frustra o desenvolvimento efetivo da personalidade humana (FACHIN, 2015, p. 154).

Por derradeiro, na Lei da Adoção percebe-se a importância dada ao desenvolvimento psíquico da criança e do adolescente no que concerne à inserção no âmbito da família substituta. Também a Lei de Alienação Parental busca vedar a interferência prejudicial na formação psicológica da criança ou do adolescente.

Destarte, em que pese o afeto não desponte, na maioria das vezes, de forma explícita, ele se encontra permeando o cenário constitucional e legislativo, sendo também usado como fundamento para decisões judiciais, como o reconhecimento da união homoafetiva (ADI n ${ }^{\circ} 4.277 / \mathrm{DF}$ ), em que se reconheceu o valor do afeto como inerente à dignidade humana; e do reconhecimento da paternidade socioafetiva no julgamento pelo Supremo Tribunal Federal da Repercussão Geral $n^{\circ}$ 622.

Assim, embora não expresso, o afeto sempre está a guiar os métodos da hermenêutica, uma vez que a afetividade é inerente ao ser humano e os laços que dela advém são naturais.

\section{O VALOR DO AFETO: A DIGNIDADE DA PESSOA HUMANA E O ABANDONO AFETIVO}

Embora em tempos pretéritos o afeto - apesar de existir - não demandasse a mesma importância, afirma-se uma mudança paradigmática com a Constituição Federal de 1988, a qual trouxe contornos a um constitucionalismo democrático, onde há a combinação de uma soberania popular e o respeito aos direitos fundamentais (BARROSO, 2017, p. 536).

Sérgio Resende de Barros define o afeto como um liame que comunica as pessoas mesmo quando estas estejam distantes no tempo e no espaço (BARROS, 2002). Com o advento da Constituição Federal de 1988 fala-se em uma constitucionalização do Direito Civil, em que a tutela do Estado se volta não mais às instituições e patrimônio, mas sim à pessoa humana em si, especialmente no tocante à realização de sua dignidade.

\footnotetext{
${ }^{3}$ Art. 5o Para os efeitos desta Lei, configura violência doméstica e familiar contra a mulher qualquer ação ou omissão baseada no gênero que the cause morte, lesão, sofrimento físico, sexual ou psicológico e dano moral ou patrimonial:

$[\ldots]$

III - em qualquer relação íntima de afeto, na qual o agressor conviva ou tenha convivido com a ofendida, independentemente de coabitação.
} 
É em face dessa mudança epistemológica, que a ordem jurídica passou a atribuir relevância ao afeto, o qual angariou então o caráter de valor jurídico. Villela (1980) foi o primeiro autor a introduzir o afeto como valor jurídico ainda na década de 70, pré-constituição de 1988, quando tratou acerca da desbiologização da paternidade, consagrando que esta "reside antes no serviço e no amor que na procriação" (PEREIRA, 2005, p. 10-11).

Com a Constituição Federal de 1988, o primeiro a retomar esse caminho do afeto como valor jurídico foi Luiz Edson Fachin (1998), seguido por Giselda Hironaka (1999), Maria Berenice Dias (1999) e Sérgio Resende de Barros (2002). Porém, no ano 2000, em um Congresso de Direito de Família promovido pelo IBDFAM - Instituto Brasileiro de Direito de Família, Paulo Luiz Netto Lôbo defendeu o afeto como sendo um princípio jurídico (PEREIRA, 2005, p. 11-12).

Do respeito aos direitos fundamentais insertos na Constituição, o primeiro ponto a denotar importância e reconhecimento ao afeto é a própria dignidade da pessoa humana. A vinculação entre esta e os direitos fundamentais já é uma premissa, na qual se baseia o direito constitucional contemporâneo (SARLET, 2006, p. 26), donde, inclusive, se percebe um sistema jurídico voltado precipuamente à proteção da pessoa em si.

Os direitos fundamentais, os quais estão diretamente relacionados à dignidade da pessoa humana, são núcleo elementar da pessoa, no qual se insere a própria integridade física e psíquica (SANTOS, 2009, p. 198). Não há como se pensar em qualquer direito de forma desprendida da dignidade humana. Outrossim, o artigo $1^{\circ}$ da Constituição Federal de 1988 é silente ao dispor a dignidade da pessoa humana como um dos fundamentos do Estado Democrático de Direito, de onde, pois, se infere que o próprio Estado Democrático de Direito não pode se desprender da ideia de realização da dignidade humana e consequentemente dos próprios direitos fundamentais.

Sarlet (2006, p. 77) salienta que uma das funções exercidas pelo direito fundamental à dignidade humana está na atribuição de unidade de sentido e legitimidade a uma ordem constitucional.

As relações de afeto fazem parte da própria trajetória da pessoa humana e esta, como já informado, se consubstancia como eixo de proteção do ordenamento jurídico; e, sendo a estrutura psíquica (de onde decorrem as relações de afeto) intrínseca à personalidade, outro resultado não há senão o de que da proteção dessa estrutura decorra a própria proteção da pessoa e sua dignidade, uma vez que "a afetividade se constitui num princípio que rege todas as ações na vida em sociedade e se prende diretamente ao princípio fundamental da dignidade da pessoa humana" (SANTOS, 2009, p. 199).

Portanto, dessa necessidade de proteção da dignidade humana decorre o direito fundamental ao afeto. O ser humano forma-se por laços genéticos, afetivos e ontológicos, o que faz da condição humana uma condição tridimensional, reflexo da conjuntura e da própria dignidade humana, ao 
passo que essas três dimensões se tornam tão irrevogáveis quanto a vida, correspondendo a uma parte da própria trajetória humana (WELTER, 2012).

Ainda, complementarmente à proteção da dignidade humana em si, o reconhecimento e consequentemente a relevância do direito ao afeto como fundamental pode ser inferido do tema recorrente na atualidade da responsabilização por abandono afetivo, que também envolve a questão da proteção da dignidade.

A sobrevivência humana depende da interação do afeto, o qual é valor supremo, de extrema necessidade, o que se extrai, não só, mas principalmente, das demandas ajuizadas no Poder Judiciário a fim de averiguar a responsabilidade civil pela falta de afeto (MADALENO, 2015, p. 104).

Em 2012, o Superior Tribunal de Justiça condenou um pai a indenizar sua filha no valor de $\mathrm{R} \$ 200.000,00$ (duzentos mil reais) por abandono afetivo ${ }^{4}$. Em primeira instância a autora teve seu pedido julgado improcedente, atribuindo como causa do distanciamento entre pai e filha o comportamento de sua mãe. Dessa decisão recorreu a autora e obteve provimento de sua apelação pelo Tribunal de Justiça de São Paulo, que condenou o réu na monta de $\mathrm{R} \$ 415.000,00$ (quatrocentos e quinze mil reais), reconhecendo, pois, o abandono afetivo.

Contudo, o pai interpôs Recurso Especial perante o Superior Tribunal de Justiça alegando afronta aos artigos 159 do Código Civil de 1916 (correspondente ao artigo 186 do Código Civil de $2002^{5}$ ), $944^{6}$ e $1.638^{7}$ do Código Civil de 2002, arguindo como um de seus fundamentos que caso houvesse abandonado sua filha, referido abandono afetivo não se revestia de ilicitude (necessária à configuração de responsabilidade civil) fato que afastaria a condenação ao pagamento de indenização por dano moral.

A Ministra Nancy Andrighy, relatora do recurso, ressaltou de início que não há óbices à aplicação da responsabilização civil com o resultante dever de indenizar na seara do Direito de Família. Para ela o elo entre pais e filhos é fruto de um ato de vontade (seja para o nascimento ou adoção), que gera, portanto, uma responsabilidade. Assim, pais e filhos estariam ligados tanto pelo vínculo afetivo como legal, donde decorrem o dever de cuidado, convívio, criação e educação, que concorrem tanto na manutenção física como psíquica dos filhos. A ilicitude advém da própria

\footnotetext{
${ }^{4}$ REsp 1.159.242/SP

${ }^{5}$ Art. 186. Aquele que, por ação ou omissão voluntária, negligência ou imprudência, violar direito e causar dano a outrem, ainda que exclusivamente moral, comete ato ilícito.

${ }^{6}$ Art. 944. A indenização mede-se pela extensão do dano.

${ }^{7}$ Art. 1.638. Perderá por ato judicial o poder familiar o pai ou a mãe que:

I - castigar imoderadamente o filho;

II - deixar o filho em abandono;

III - praticar atos contrários à moral e aos bons costumes;

IV - incidir, reiteradamente, nas faltas previstas no artigo antecedente.

$\mathrm{V}$ - entregar de forma irregular o filho a terceiros para fins de adoção.
} 
obrigação legal de cuidado, ao passo que, em suas palavras, a discussão cinge-se não na imposição de amar, mas na imposição de cuidar como um dever jurídico daqueles que geram ou adotam filhos.

Assim, estariam configurados todos os requisitos necessários à responsabilidade civil, neste caso, por abandono afetivo. A ilicitude estaria na negligência com o dever de cuidado. $\mathrm{O}$ dano e o nexo causal necessários para a caracterização da responsabilidade são extraídos de laudo que aponte para uma patologia psíquica relacionada a essa negligência pelos pais ou um deles, ou fatos que decorram do próprio caso concreto, como reconhecimento forçado da paternidade e ausência de qualquer contato. Por todas essas razões foi dado parcial provimento ao recurso, apenas para diminuir para o valor de $\mathrm{R} \$ 200.000,00$ (duzentos mil reais) a quantia inicialmente arbitrada pelo TJSP.

Ainda, no tocante a essa questão, importante mencionar o projeto de Lei ${ }^{\circ}$ 4.294/2008, apresentado pelo Deputado Carlos Bezerra em novembro de 2008, que pretende acrescentar um parágrafo ao artigo 1.632 do Código Civil, bem como ao artigo $3^{\circ}$ do Estatuto do Idoso, a fim de que passe a constar de forma explícita que o abandono afetivo sujeita ao pagamento de indenização por dano moral. Contudo, o mesmo ainda se encontra adstrito à apreciação pelas comissões ${ }^{8}$.

A responsabilização por abandono afetivo é apenas mais um dos indícios a argumentar a fundamentalidade do direito ao afeto. $\mathrm{O}$ abandono afetivo decorre, portanto, de uma conduta omissiva praticada pelos pais em relação aos filhos, baseada nos artigos 186 e 927 do Código Civil, artigo 229 da Constituição Federal e artigo 1.634, I do Código Civil, que impõem o dever de criação e educação. Os danos daí decorrentes vinculam-se aos direitos da personalidade, bem como à proteção da dignidade humana. $\mathrm{O}$ nexo causal advém da determinação da omissão dos pais como causa adequada ao abalo psíquico do filho (SANTOS, 2009, p. 205-208).

Saliente-se que os casos de abandono afetivo não intentam "impor um valor ao amor, mas reconhecer que o afeto é um bem que tem valor" (DIAS, 2013, p. 470).

$\mathrm{O}$ afeto, portanto, seja embasado na dignidade humana em si, seja nos casos de abandono afetivo, nos quais também incide a própria questão da dignidade e consequente desenvolvimento da personalidade, é um direito que requer seu reconhecimento no plano da fundamentalidade. Já que todos os direitos fundamentais "remontam à ideia de proteção e desenvolvimento das pessoas" (SARLET, 2006, p. 79) com o afeto não ocorre de modo diferente.

É nesse contexto que aqui, pois, se pretende conceber o afeto como "um direito individual: uma liberdade, que o Estado deve assegurar a cada indivíduo, sem discriminações, senão as mínimas necessárias ao bem comum de todos" (BARROS, 2010), dotado de fundamentalidade.

\footnotetext{
${ }^{8}$ Informação retirada da página de projetos de leis e outras proposições da Câmara dos Deputados. Disponível em: $<$ http://www.camara.gov.br/proposicoesWeb/fichadetramitacao?idProposicao=415684>.
} 
Importante ressaltar que do afeto podem-se extrair duas dimensões: uma subjetiva que corresponde ao sentimento em si, a qual deverá sempre ser presumida no campo do Direito; e a objetiva, que corresponde ao fato social (ao expressar-se de modo afetivo) (CALDERÓN, 2016). No campo jurídico a importância de constatação recai sobre a dimensão objetiva, uma vez que sendo esta identificada a dimensão subjetiva se presume.

Para Sérgio Resende de Barros o direito ao afeto é o "mais imprescindível à saúde física e psíquica, à estabilidade econômica e social e ao desenvolvimento material e cultural da família e do seu lar" (BARROS, p. 614, 2004), e, portanto, da própria pessoa humana, o que acaba por atar o seu caráter fundamental.

Sendo assim, considerando as dimensões de direitos fundamentais - sejam três, quatro, cinco ou seis, a variar de autores - e tomando o afeto como vital ao desenvolvimento da pessoa humana e de sua personalidade (desenvolvimento psíquico), inseri-lo de modo restrito em uma destas seria minar a sua existência ao longo da humanidade. Em que pese se afirme que seu reconhecimento tenha angariado força com a Constituição Federal de 1988, resta indubitável que o afeto caminhou por todas as dimensões (ou gerações) e não se restringe à terceira referente ao princípio da solidariedade. A humanidade não existe desvinculada de afeto - pois que o ser humano não é apenas ser, mas antes de tudo é sentir (WELTER, 2012).

Conforme elucida Leonardo Boff (2008, p. 8), o afeto liga-se ao surgimento dos mamíferos há 125 milhões de anos quando do aparecimento do cérebro límbico, ao passo que somente nos últimos 5-7 milhões de anos surgiu o néo-cortex responsável pela racionalidade, sendo este, portanto, recente demais para se igualar à importância das emoções.

$\mathrm{O}$ direito ao afeto passa cada vez mais a alargar suas barreiras e atingir novos e mais sujeitos e objetos, na medida em que ao longo da história sua necessidade se torna premente na realização da pessoa humana e de sua dignidade nas mais variadas situações.

\section{CONCLUSÃO}

O que aqui não se questiona, mas, inclusive, se ratifica, é o marco do reconhecimento do afeto na Constituição Federal de 1988. Contudo, apesar do mencionado reconhecimento, é imprescindível atentar-se ao fato de que o afeto, muitas vezes, é visto apenas no campo valorativo, mas não como um direito.

Ocorre que o Direito deve ser reflexo das relações entre os sujeitos no tempo e no espaço. Bobbio, em sua obra “A Era dos Direitos” já apontava que no futuro poderiam (e, ressalte-se, ainda virão), emergir novas pretensões das quais se emergiriam novos direitos, donde se extrai que não existem direitos fundamentais por natureza (2014, p. 13). 
Assim é que o afeto se constitui como um direito individual que a despeito de não expresso no texto constitucional, nele encontra-se implícito. $\mathrm{O} \S 2^{\circ}$ do artigo $5^{\circ}$ da Constituição é silente ao dispor que os direitos e garantias nela expressos não exclui outros que venham a decorrer do regime e dos princípios adotados. No que se refere, pois, aos direitos fundamentais, o seu aspecto formal é insuficiente, podendo, inclusive, não corresponder à realidade (FERRAJOLI, 2011, p. 10).

É nesse sentido que aqui se defende a fundamentalidade do direito ao afeto, embora não haja qualquer dispositivo que faça referência ao direito ao afeto no rol de direitos e garantias fundamentais da Constituição. Estar ou não disposto no texto constitucional não é condição imprescindível para atribuição de fundamentalidade a um direito. A fundamentalidade não é característica que se atribui de maneira desvinculada da realidade posta (BIELSCHOWSKY, 2015, p. 87).

O destaque para a presença do afeto na Constituição, bem como na legislação infraconstitucional volta-se no que concerne aos chamados grupos vulneráveis que dependem de uma tutela específica. Nesse caso aponta-se para as crianças e os adolescentes, os idosos e as pessoas com deficiência. Não apenas referidos grupos ilustram a presença do afeto, mas também as próprias relações de famílias, que hoje fundam-se precipuamente no afeto em detrimento do matrimônio ou de previsão legal.

$\mathrm{O}$ valor galgado pelo afeto como direito fundamental encontra fundamento na própria necessidade de proteção e respeito à dignidade da pessoa humana. $\mathrm{O}$ afeto é ínsito ao ser humano, ao passo que negar ou tolher o direito ao afeto é o mesmo que violar a própria dignidade da pessoa humana, fundamento do Estado Democrático de Direito, disposto no artigo $1^{\circ}$ da Constituição Federal. Ainda, a ilustrar mencionado valor vêm à tona no âmbito do Poder Judiciário Brasileiro as ações de abandono afetivo. "O órgão do cuidado é o afeto" (BOFF, 2008, p. 8). A Constituição Federal e as legislações infraconstitucionais (Código Civil e Estatuto da Criança e do Adolescente), dispõem aos pais poderes paternos em relação aos filhos, contudo dos poderes advêm deveres, entre os quais, encontra-se o dever de cuidado, que se violado pode gerar danos aos filhos de ordem moral, atingindo o desenvolvimento psíquico, donde decorre a responsabilização por abandono afetivo.

A despeito dos recortes específicos aqui realizados quanto aos grupos vulneráveis, o afeto é essencial ao desenvolvimento digno da personalidade, o que sedimentado o afeto como um direito fundamental.

Considerando, ainda, as dimensões em que se colocam os direitos fundamentais, ao invés de pretender o afeto como objeto de reconhecido restrito a apenas uma destas dimensões, no caso, a terceira dimensão que abrange a solidariedade e os direitos difusos, o que se pode concluir é que o direito fundamental ao afeto deve ser considerado como um direito interdimensional (ou 
intergeracional a depender da denominação adotada), objeto de reconhecimento em todas as dimensões de direitos fundamentais ao longo da sociedade.

"A vantagem maior do afeto é a possibilidade da realização da ternura na vida de cada um, nos momentos de paz e nas ameaças de conflito" (CUNHA, 2003, p. 86). O afeto é imprescindível ao desenvolvimento da pessoa humana, inclusive, de suma importância ao desenvolvimento psíquico, embora se reconheça a Constituição Federal de 1988 como marco de sua inserção no cenário jurídico, miná-lo a uma só dimensão seria negar a sua necessidade e existência em tempos pretéritos para realização e proteção da dignidade humana.

É possível sim, portanto, o reconhecimento de um direito fundamental interdimensional ao afeto, imanente à pessoa humana, sem o qual não é possível o pleno e digno desenvolvimento da personalidade, seja através da inclusão, do reconhecimento das mais variadas formas de famílias ou da imposição de um dever de cuidado.

\section{INTERDIMENSIONAL FUNDAMENTAL RIGHTS TO AFFECT}

Abstract: Fundamental rights are endowed with historicity, and for that they are recognized and inserted in generations / dimensions. There is much talk about the recognition of the affection for the Law with the advent of the Federal Constitution of 1988, although it does not have express provision in the constitutional text. Affection is inherent to the human person, so they cannot be thought of in an unrelated way, being essential to the protection of human dignity and to its psychic development. In this context, this article aims to analyze and understand affection as a right endowed with a recognized fundamentality in all the dimensions of fundamental rights pointed out by the current doctrine. It is a theoretical and qualitative research, which uses as a means the bibliographical and documentary revision.

Keywords: Fundamental right; affection; dimensions

\section{REFERÊNCIAS}

ALEXY, Robert. Teoria dos Direitos Fundamentais. São Paulo: Malheiros, 2008.

BARBOZA, Heloisa Helena. Vulnerabilidade e Cuidado: aspectos jurídicos. In: PEREIRA, Tânia da Silva; OLIVEIRA, Guilherme de. Cuidado \& Vulnerabilidade. São Paulo: Atlas, 2009.

BARROS, Sérgio Resende de. A ideologia do afeto. Revista Brasileira de Direito de Família. Porto Alegre: Síntese, IBDFAM, v. 4, n. 14, p. 9, jul/set 2002. 
. Direitos Humanos da Família: dos fundamentais aos operacionais. In: PEREIRA, Rodriga da Cunha (coord.). Afeto, Ética, Família e o novo Código Civil. Belo Horizonte: Del Rey, 2004, p. 607-620.

O direito ao afeto. Disponível em: < http://www.srbarros.com.br/pt/o-direito-aoafeto.cont>. Acesso em 13 de dezembro de 2017.

BARROSO, Roberto Luís Roberto. Curso de direito constitucional contemporâneo: os conceitos fundamentais e a construção do novo modelo. 6 ed. São Paulo: Saraiva, 2017. Disponível em: <https://integrada.minhabiblioteca.com.br/\#/books/9788547218546/>. Acesso em 20 de dezembro de 2017.

BIELSCHOWSKY, Raoni Macedo. Notas sobre a jusfundamentalidade: ou apontamentos sobre o problema de todo direito ser considerado fundamental. Revista de Informação Legislativa, Brasília a. 52 n. 208 out./dez. 2015.

BOBBIO, Norberto. A era dos direitos. Rio de Janeiro: Elsevier, 2004. Disponível em: < https://edisciplinas.usp.br/pluginfile.php/297730/mod_resource/content/0/norberto-bobbio-a-erados-direitos.pdf $>$. Acesso em 14 de outubro de 2017.

BOFF, Leonardo. Justiça e Cuidado: Opostos ou Complementares? In: PEREIRA, Tânia da Silva; OLIVEIRA, Guilherme de (coord.). O cuidado como valor jurídico. Rio de Janeiro: Forense, 2008.

BONAVIDES, Paulo. Curso de direito constitucional. São Paulo: Malheiros, 2004.

A quinta geração de direitos fundamentais. Disponível em: < http://www.ufjf.br/siddharta_legale/files/2014/07/Paulo-Bonavides-A-quintagera $\% \mathrm{C} 3 \% \mathrm{~A} 7 \% \mathrm{C} 3 \% \mathrm{~A} 30-$ de-direitos-fundamentais.pdf $>$. Acesso em 15 de dezembro de 2017.

BRASIL. Constituição da República Federativa do Brasil de 1988. Disponível em: < http://www.planalto.gov.br/ccivil_03/constituicao/constituicao.htm>. Acesso em 14 de novembro de 2017.

. Lei $\mathrm{n}^{\mathbf{0}}$ 10.406, de 10 de janeiro de 2002. Institui o Código Civil. Disponível em: < http://www.planalto.gov.br/CCivil_03/leis/2002/L10406.htm>. Acesso em 14 de novembro de 2017.

Lei $\mathbf{n}^{\circ} \mathbf{1 0 . 7 4 1}$, de $1^{\circ}$ de outubro de 2003. Dispõe sobre o Estatuto do Idoso e dá outras providências. Disponível em: < http://www.planalto.gov.br/ccivil_03/leis/2003/110.741.htm>. Acesso em 14 de novembro de 2017.

Lei $n^{0}$ 11.340, de 7 de agosto de 2006. Cria mecanismos para coibir a violência doméstica. Disponível em: < http://www.planalto.gov.br/ccivil_03/_ato2004-2006/2006/lei/111340.htm>. Acesso em 14 de novembro de 2017.

. Lei $\mathbf{n}^{0}$ 13.146, de 6 de julho de 2015. Institui a Lei Brasileira de Inclusão da Pessoa com Deficiência (Estatuto da Pessoa com Deficiência). Disponível em: < http://www.planalto.gov.br/ccivil_03/_ato2015-2018/2015/lei/113146.htm>. Acesso em 14 de novembro de 2017. 
. Lei n 12.318, de 26 de agosto de 2010. Dispõe sobre a alienação parental e altera o art. 236 da Lei $\mathrm{n}^{\mathrm{o}}$ 8.069, de 13 de julho de 1990. Disponível em: < http://www.planalto.gov.br/ccivil_03/_ato2007-2010/2010/lei/112318.htm>. Acesso em 14 de novembro de 2017.

. Lei $\mathbf{n}^{\circ}$ 8.069, de 13 de julho de 1990. Dispõe sobre o Estatuto da Criança e do Adolescente e dá outras providências. Disponível em: http://www.planalto.gov.br/ccivil_03/leis/L8069Compilado.htm>. Acesso em 14 de novembro de 2017.

Projeto de Lei $\mathbf{n}^{\mathbf{0}}$ 4294/2008. Acrescenta parágrafo ao art. 1.632 da Lei $\mathrm{n}^{\mathrm{o}} 10.406$, de 10 de janeiro de 2002 - Código Civil e ao art. $3^{\circ}$ da Lei $n^{\circ} 10.741$, de $1^{\circ}$ de outubro de 2003 - Estatuto do Idoso, de modo a estabelecer a indenização por dano moral em razão do abandono afetivo. Disponível em:

http://www.camara.gov.br/proposicoesWeb/fichadetramitacao?idProposicao=415684>. Acesso em 02 de dezembro de 2017.

Recurso Especial $n^{0}$ 1.159.242-SP (2009/0193701-9). Rel. Ministra Nacy Andrighi. Disponível em: < http://www.migalhas.com.br/arquivo_artigo/art20120510-02.pdf $>$. Acesso em 12 de dezembro de 2017.

Ação Direta de Inconstitucionalidade 4.277 Distrito Federal (ADI $n^{0}$ 4.277). Rel. Ministro $\quad$ Ayres
http://redir.stf.jus.br/paginadorpub/paginador.jsp?docTP=AC\&docID=628635>. Acesso em 12 de
dezembro de 2017.

Repercussão Geral 622 (Prevalência da paternidade socioafetiva em detrimento da paternidade biológica. Rel. Ministro Luiz Fux. Disponível em: < http://www.stf.jus.br/portal/jurisprudenciarepercussao/verAndamentoProcesso.asp? incidente $=425$ $2676 \&$ numeroProcesso $=692186 \&$ classeProcesso $=$ ARE\&numeroTema $=622>$. Acesso em 12 de dezembro de 2017.

CALMON, Eliana. Dimensões do Direito Contemporâneo. São Paulo: IOB, 2001.

CALDERÓN, Ricardo. Afetividade e cuidado sob as lentes do Direito. In: PEREIRA, Silva, T. D., COLTRO, Mathias, A. C., OLIVEIRA, (orgs.). Cuidado e Afetividade - Projeto Brasil/Portugal 2016-2017. São Paulo: Atlas, $2017 . \quad$ Disponível em $<$ https://integrada.minhabiblioteca.com.br/\#/books/9788597009408/>. Acesso em 10 de dezembro de 2017.

CUNHA, João Paulo. A ética do afeto. In: GROENINGA, Giselle Câmara; PEREIRA, Rodrigo da Cunha (coord.). Direito de Família e Psicanálise - rumo a uma nova epistemologia. Rio de Janeiro: Imago, 2003, p. 81-86.

DIAS, Maria Berenice. Manual do Direito das Famílias. $9^{\text {a }}$ ed. São Paulo: Revista dos Tribunais, 2013, p. 70.

DINIZ, Maria Helena. Curso de Direito Civil Brasileiro. Direito de Família. Vol. 5. $27^{\text {a }}$ ed. São Paulo: Saraiva, 2012.

FACHIN, Luiz Edson. Direito Civil: sentidos, transformações e fim. Rio de Janeiro: Renovar, 2015. 
FACHIN, Zulmar; SILVA, Deise Marcelino da. Acesso à Água Potável: direito fundamental de sexta geração. São Paulo: Millennium.

FERRAJOLI, Luigi. Por uma teoria dos direitos e dos bens fundamentais. Tradução: Alexandre Salim et al. Porto Alegre: Livraria do Advogado, 2011, p. 10

LORENZETTI, Ricardo. Fundamentos do Direito Privado. São Paulo: Revista dos Tribunais, 1998.

MADALENO, Rolf. Curso de direito de família. Rio de Janeiro: Forense, 2015.

MORAES, Guilherme Peña de. Curso de Direito Constitucional. 8 ed. São Paulo: Atlas, 2016. Disponível em:

https://integrada.minhabiblioteca.com.br/\#/books/9788597005523/cfi/6/94!/4@0.00:0.00>.

Acesso em 20 de outubro de 2017.

NOGUEIRA, Alberto. A Reconstrução dos Direitos Humanos da Tributação. Rio de Janeiro: Renovar, 1997.

OLIVEIRA JÚNIOR, José de. Teoria Jurídica e Novos Direitos. Rio de Janeiro: Lumen Juris, 2000.

PEREIRA, Rodrigo da Cunha. Princípios fundamentais norteadores para o direito de família. Belo Horizonte: Del Rey, 2005.

. Pai, por que me abandonaste? In: GROENINGA, Giselle Câmara; PEREIRA, Rodrigo da Cunha (coord.). Direito de Família e Psicanálise - rumo a uma nova epistemologia. Rio de Janeiro: Imago, 2003, p. 219-228.

RODOTÁ, Stefano. Diritto d'amore. Bari: Laterza, 2015.

Il diritto di avere diritti. Bari: Laterza, 2015.

PEREIRA, Tânia da Silva. Direito da criança e do adolescente - uma proposta interdisciplinar. Rio de Janeiro: Renovar, 2008

SANTOS, Romualdo Baptista dos. Responsabilidade civil na parentalidade. In: HIRONAKA, Giselda Maria Fernandes Novaes; TARTUCE, Flávio; SIMÃO, José Fernando (Coord.). Direito de Família e das Sucessões. São Paulo: Método, 2009, p. 191-214.

SARLET, Ingo Wolfgang. Dignidade da pessoa humana e direitos fundamentais na Constituição Federal de 1988. 4 ed. Porto Alegre: Livraria do Advogado Editora, 2006. Disponível $\mathrm{em}: \quad<\mathrm{https}$ ://www.passeidireto.com/arquivo/4065026/ingo-wolfgang-sarlet---dignidade-dapessoa-humana-e-direitos-fundamentais-na-com>. Acesso em 20 de outubro de 2017.

. A eficácia dos direitos fundamentais: uma teoria geral dos direitos fundamentais na perspectiva constitucional. 11 ed. Porto Alegre: Livraria do Advogado Editora, 2012. Disponível em: < https://www.passeidireto.com/arquivo/6221261/a-eficacia-dos-direitos-fundame---ingowolfgang-sarlet $>$. Acesso em 20 de outubro de 2017.

SILVA, José Afonso da. Curso de direito constitucional positivo. 20 ed. São Paulo: Malheiros, 2002. 
SYMONIDES, Janusz. Direitos Humanos. Brasília: UNESCO Brasil, 2003, p. 32

WELTER, Belmiro Pedro Marx. Teoria Tridimensional do Direito de Família. Revista do Ministério Público do RS. Porto Alegre, n. 71, janeiro a abril de 2012, p. 127-148. Disponível em: $<$ http://www.amprs.org.br/arquivos/revista_artigo/arquivo_1342124687.pdf $>$. Acesso em 03 de novembro. de 2017.

Trabalho enviado em 12 de fevereiro de 2019 Aceito em 14 de maio de 2020 